\title{
Discussion on the Employment Probation Action and Its Radiation Effects
}

\author{
Lixin Jiang, Yang Hu, Ying Zhou \\ Dalian Polytechnic University, Dalian, 116034, China
}

Keywords: college students; employment probation; radiation effects; tentative discussion

\begin{abstract}
To guarantee the effect of college student employment probation action, it is required to carry out elaborate planning, careful investigation and scientific organization. Implementation of the college student employment probation action plan can give full play to its radiation effects such as guiding students' all-around development, carrying forward the ideological and political education to college students, promoting the college student employment guidance and driving the industry-college-institute cooperation, and achieve the all-win situation among colleges, enterprises and students. To enrich college students' social practice experience and improve their employment competitiveness, according to the spirits of the Notice on Carrying Out the College Student Employment Probation Action in Liaoning Province issued jointly by the Communist Youth League Committee of Liaoning Province and the Liaoning Provincial Committee of Education and in accordance with colleges' relevant requirements, our college has been carrying out the college student employment probation action for one month in summer of each year since 2007 in such engineering fields as light-chemical industry, packaging, foods, chemical, textile, etc. From the summarization and analysis on the several years of college student employment probation action, we have seen that the college student employment probation action has not only promoted college students' all-round development, but also exerted a great radiation effect on college students' ideological and political education and employment guidance, industry-college-institute cooperation and other works.
\end{abstract}

\section{Organization and management of employment probation action}

The employment probation action that can achieve good results requires elaborate planning, careful investigation and scientific organization. Especially, effective guarantee should be provided in terms of college students' personal safety and obtaining reasonable benefits. It is required to not only provide students with practice opportunities, but also prevent them from becoming cheap labor force.

\section{Full preparation and strict selection}

Firstly, widely mobilize professional teachers to recommend probation enterprises that fit in with students' specialties, get in touch with the recommended enterprises and send teachers to such enterprises for field trips after approval, so as to make clear the working environment and accommodation condition of factories and students' specific work tasks. On this basis, determine the enterprises and the number of students for probation. In order to guarantee the probation effect and students' safety, probation enterprises we determined should meet these requirements: normal production, operation and work, standard management; capable of providing corresponding probation positions and conditions; high-tech and strong-specialty probation positions; having scientific probation management methods and professional instructors. Then, organize students for voluntary registration, select excellent students with high ideological quality and solid specialty knowledge from those registered ones, and recommend them to the probation enterprises for probation. In this way, it can guide students to learn the theoretical knowledge in a better way and prevent some students from paying more attention to probation and practice than to school work, just like putting the cart before the horse.

2. Signing the "Employment Probation Agreement"

In order to guarantee the probation effect and students' safety, the College Student Employment 
Probation Action Agreement should be signed among the employed student's college, the probation enterprise and the probationer before the probationer formally starts his probation work, so as to make clear the responsibilities, rights and obligations of the probation enterprise, the probationer and the college and to request the probation enterprise to provide students with probation positions and reasonable working subsidies, take charge of students' job training, safety education and daily management and assign special persons for probationers' management and instruction. The probation enterprise should be responsible for students' physical injuries due to the probation enterprise's reasons under students' normal work condition. Probationers are required to pay attention to their own safety, earnestly take part in job training and safety education organized by the probation enterprise, and abide by the probation enterprise's various arrangements. Probationers participating in the employment probation action should also have permissions from and always keep in touch with their parents. The college should be responsible for students' safety education prior to their probation and for uniformly arranging personal accident insurance, hospitalization medical insurance, etc. for students in their probation period.

\section{Management and assessment}

The college has prepared strict management and assessment systems for college student employment probation action and probationers from different universities. All relevant universities have established their own performance assessment teams consisting of relevant department head, head of professional teaching and research section, instructor, guiding teacher and relevant staff of the probation enterprise, raised specific requirements on probationers' working attitude, working time workload, and also prepared the system of going to the probation enterprise to visit and investigate probationers' working condition; finally, the assessment and evaluation on probationers are carried out on the basis of combining the investigation results, work evaluation by the probation enterprise, completion condition of probationers' probation diary, probation summarization report, etc. After the probation action is finished every year, the commendation conference is held to summarize the experience, improve the system and optimize the scheme.

\section{Radiation effects of employment probation action}

\section{Employment probation action is an effective way to guide students' all-round development}

Quality-oriented education regards students' growth and development as the growth of a person's whole life and considers a person's all-round development as the ultimate purpose of education. The all-round development refers to students' overall development in moral, intellectual, physical, aesthetic, labor and other aspects as well as their quality [1]. In the market economy conditions, college graduates require not only extensive and solid basic knowledge, but also various necessary skills for their employment. Therefore, cultivating graduates with strong social adaptation ability becomes an urgent need of improving the teaching quality, and is an actual requirement for enhancing graduates' employment competitiveness [2]. By means of participating the employment probation action, college students can build their correct views on the world, life and value in a better way; this action has cultivated their sense of responsibility and spirit of hard working, further enhanced their senses of organizational discipline and workplace specification, improved their application ability of integrating theory with practice, strengthened their sense of practice that makes them master the specialized knowledge in a more solid way, further cultivated their senses of responsibility and teamwork, trained their interpersonal skills, made them understand the enterprise organization culture in a more profound way, exercised their physical prowess, improved their psychological quality, made them discover their own disadvantages and understand the direction of efforts, enhanced their professional consciousness and more practical employment concept and strengthened their will to fight. The employment probation action has promoted college students' all-round development and enhanced colleges' teaching quality.

2. Employment probation action is an effective carrier of promoting the college students' ideological and political education work

In the National Conference on Strengthening and Improving the College Students' Ideological 
and Political Education Work, President Hu Jintao stressed to persist in combination of education and self-education for purposes of not only giving full play to college's education and guidance, but also fully mobilizing students' enthusiasm and initiative, to persist in combination of political theory education and social practice for the sake of not only accomplishing a favorable classroom education, but also paying attention to guiding college students to go deep into, understand and serve the society. It is also required to actively explore new methods for college students' ideological and political education work under the new situation. Employment probation action is a good opportunity not only for students' self-education, but also for going deep into and understanding the society. Taking the employment probation as the carrier of college students' ideological and political education is more targeted and effective.

Employment probation shortens the distance between students and enterprises. In the probation period, students will not only learn more specialized knowledge and accumulate practical experience, but also know themselves and the gap between themselves and the social needs in a more comprehensive way. All that they saw and heard in the probation period will have a certain impact on their inherent cognition and result in psychological and ideological conflicts; therefore, their self-perception needs to be changed and improved. Such change and improvement require not only the self-realization, but also the education and guidance by ideological education staff. It is required to guide students to learn in a diligent and step-by-step way when they firstly step into employment probation activities, to tell them to be persevering and persistent when they have the idea of giving up due to their own factors, and to instruct them to timely have a timely summarization and deep thinking when they accomplish the employment probation and get back with joy. The college students' ideological and political education work should run throughout the whole employment probation action and should be carried out according to actual circumstances, so that college students are ideologically improved and further behaviorally matured.

\section{Employment probation action is a effective platform to promote the college student} employment guidance work.

Occupational career planning of college students is the personal development process from self-perception and self-affirmation and finally to self-realization [3]. According to a survey, students in college are generally lack of the sense of occupational career planning; participating in the employment probation action can make students know themselves in a more comprehensive and deeper way, is good for strengthening students' understanding on enterprise demands and for making students form correct senses of job selection and employment, and has enhanced their initiative and scientificity in occupational career planning; in front of employment and job selection, they can get the entry and breakthrough points and accurately determine their positions in a better way as well as select industries and posts suitable for them.

Students have not sufficiently mastered commonsense issues such as resume preparation, writing of self-recommendation letter, preparation for interview, basic etiquette for employment, etc. during employment, feel nervous when communicating with employers and pay excessive attention to economic benefits rather than vocational outlook, long-term development, their own abilities, advantages and disadvantages, which result in blind job selection; therefore, we have added the "employment probation double-option Fair" link when organizing the employment probation activities in recent two years and simulated the whole process of employer's interview when selecting probationers, so as to let students experience the atmosphere of interview in advance and consequently strengthen the effectiveness of college student employment guidance and enhance students' employment competitiveness.

\section{Employment probation action is an effective opportunity for driving the} industry-college-institute cooperation.

According to the division from contents of cooperation, the industry-college-institute cooperation mode mainly includes: receiving and developing technologies, jointly building research institutions and labs, establishing economic entities, sharing scientific and technological resources, technical consultation and services [4].

In the process of carrying out the employment probation action, our college takes the initiative to 
contact with enterprises, has expanded the range of contact with enterprises, and actively pays a return visit to enterprises that have accepted our graduates. We go to probation enterprises for study and research at regular intervals, visiting probationers and holding forums in enterprises to communicate with students in terms of students' actual practice condition, which have further strengthened the feelings with enterprises and established a batch of new bases for college student employment probation and internship. In the process of carrying out the employment probation action, we continuously consolidate and strengthen the construction of college's employment bases, which is an effective guarantee for implementing the college student employment probation activities in a better way, an basic engineering for college student employment, and an effective carrier for carrying out the industry-college-institute and other deep exchanges and cooperation with enterprises.

In the process of seeking for probation enterprises, we extensively explore alumni resources, actively contact with schoolmates at different places and call up them to form a larger resource library. With this opportunity, we have gone deep into enterprises and schoolmates, had a deep communication with schoolmates working in enterprises, and heard their advices and suggestions on teaching, practice arrangement, etc. Different generations of schoolmates get together to recall the past in the light of the present, speak their minds freely and contribute ideas for the development of their college. Through the whole journey, we have deeply felt schoolmates' attachment and love for their college. Many schoolmates or their enterprises have provided fellowships and scholarships for relevant colleges or specialties.

Besides, the implementation of employment probation action has also expanded the way of thinking for running the colleges, and some colleges decide to strive for building the triune personnel training mode of technological innovation, employment probation and industry-college-institute cooperation and to highlight the cultivation of practice-based talents, which have promoted the implementation of the "excellent engineering cultivation plan".

In the process of carrying out the years of college student employment probation action, we continuously strengthen the relationship with enterprises, take this opportunity and utilize our college's talent advantage to discuss and implement the industry-college-institute cooperation with many enterprises in different ways such as transfer of scientific achievements, new product development, joint construction of labs, technological consultation and services, etc., form the "mutual benefit" relationship and then establish the long-term and stable industry-college-institute cooperation bases on the basis of "win-win situation".

Colleges are the bases for cultivating high-quality talents. The implementation of the college student employment probation action has quickened the effective connection between enterprises and our college students, enhanced college students' abilities to operate practically and to practice what they learnt, increased their experience in post exercise and improved their employment competitiveness [5]. It can be said that we have achieved the all-win situation among colleges, enterprises and students by taking the employment probation action as the opportunity and utilizing the joint effort and long-term cooperation between colleges and enterprises [6].

\section{References}

[1] Chen Xueli, Thinking on Implementation of Quality-oriented Education for Cultivating Engineering Professionals, Journal of Yangzhou University (Higher Education Research Version), 2001 (03).

[2] Li Dehai, Ji Gang and Qin Wei, Abilities and Quality To be Mastered by Modern College Graduates, Career Horizon, 2010 (06).

[3] Tian Xiaoyong, Zhao Donglei, Ji Meijing and An Yuhong, Analysis on Current Situation and Implementation Countermeasures of College Students' Career Design, Career Horizon, 2010 (06).

[4] Liu Zhenping, Industry-College-Institute Cooperation Mode and Mode Selection, Industrial Technological Economics, 1999 (04).

[5] Liao Tuan Lian Fa [2007] No. 22 Notice on Implementing the College Student Employment Probation Action in Liaoning Province, Apr. 22, 2007.

[6] Xu Pengbin, Exploration and Practice of New Modes for College Student Employment Probation Bases, Overseas Travel and Employment, 2010 (06). 